\title{
(3)
}

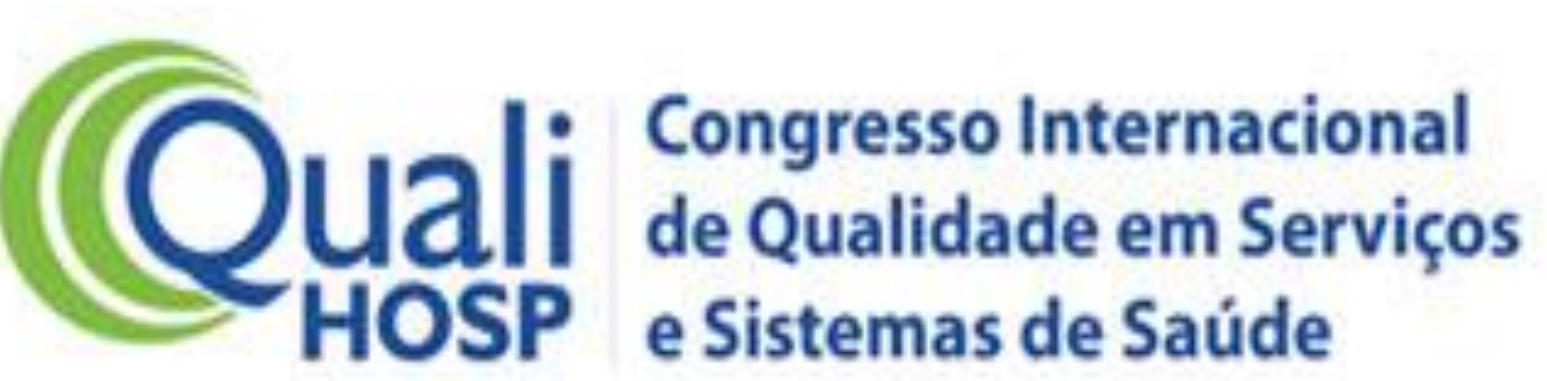

FGV EAESP

LILIANE FRANCO MORAES, MARIA CRISTINA POSE GURERRA, NATÁLIA PEIXOTO RIBEIRO, NILCEA APARECIDA OLIVEIRA, RENATA MANTOVANI

\section{REESTRUTURAÇÃO DOS KITS CIRÚRGICOS DO HOSPITAL MUNICIPAL DR. JOSÉ DE CARVALHO FLORENCE (HMJCF) UTILIZANDO A METODOLOGIA LEAN}

Eixo temático: Avaliação na qualidade do cuidado

INTRODUÇÃO: O Centro Cirúrgico é uma das unidades mais complexas de um hospital, não só por sua especificidade, mas também por ser um local fechado que expõe o paciente e a equipe de saúde a situações estressantes'. Por esse motivo é importante ter todos os materiais e equipamentos prontos para uso nas diversas cirurgias realizadas. O Kit Cirúrgico consiste em um conjunto de materiais e medicamentos utilizados para realização de qualquer procedimento cirúrgico, sendo estes fornecidos pela farmácia da Instituição. A elaboração prévia do kit cirúrgico otimiza tempo e traz segurança ao procedimento. Com intuito de tornar mais eficiente a rotina operacional do centro cirúrgico do HMJCF e diminuir a devolução de materiais dos kits cirúrgicos para a farmácia, iniciamos o trabalho de reestruturação e padronização dos kits utilizando a metodologia Lean. OBJETIVO: Atualização e padronização dos kits cirúrgicos e aumento da adesão de seu uso. METODOLOGIA: Estudo de caso utilizando e metodologia Lean para melhoria contínua. Foi aberto um A3 com reuniões semanais da equipe multidisciplinar. Realizou-se levantamento dos kits cirúrgicos com análise de todos os itens devolvidos e dos itens faltantes para realização das cirurgias através do gráfico de Pareto. Os kits foram readequados e validados pelos coordenadores de cada especialidade sendo então confeccionados pela farmácia satélite conforme agendamento do mapa cirúrgico. RESULTADOS: A reestruturação dos kits propiciou aumento na adesão de sua utilização de $44 \%$ para $100 \%$, o número de itens dentro dos kits foi reduzido em $45 \%$ e quanto a devolução obteve-se uma queda de $56 \%$ para $30 \%$ de itens devolvidos.

\begin{tabular}{|c|c|c|c|c|c|c|c|c|c|c|}
\hline & $16 / \mathrm{mar}$ & $17 / \mathrm{mar}$ & 19/mar & 20/mar & $21 / \mathrm{mar}$ & $22 / \mathrm{mar}$ & 23/mar & $26 / \mathrm{mar}$ & $27 / \mathrm{mar}$ & Total \\
\hline Kit Confeccionado & 28 & 17 & 5 & 18 & 31 & 26 & 23 & 26 & 21 & 195. \\
\hline Kit Devolvido & 14 & 10 & 0 & 13 & 22 & 18 & 20 & 17 & 14 & 128 \\
\hline Cirugias Suspensas & 2 & 3 & 0 & 2 & 3 & 0 & 3 & 4 & 1] & 18 \\
\hline \multicolumn{11}{|c|}{$\begin{array}{c}\text { Da totalidade na amostragem, verificamos que } 56 \% \text { dos kits confeccionados foram devolvidos, desconsiderando as } \\
\text { cirurgias suspensas. }\end{array}$} \\
\hline & 16/mar & $17 / \mathrm{mar}$ & 19/mar & 20/mar & $21 / \mathrm{mar}$ & $22 / \mathrm{mar}$ & 23/mar & $26 / \mathrm{mar}$ & $27 / \mathrm{mar}$ & Total \\
\hline Devolvido Intacto & 5 & 2 & 0 & 1 & 7 & 5 & 2 & 2 & 0 & 24 \\
\hline Devolvido Parcial & 9 & 8 & 0 & 12 & 15 & 13 & 18 & 15 & 14 & 104 \\
\hline Cirugias Suspensas & 2 & 3 & 0 & 2 & 3 & 0 & 3 & 4 & 1 & 18 \\
\hline \multicolumn{11}{|c|}{ Da amostragem verificamos que $4 \%$ dos kits eram devolvidos intactos e $53 \%$ eram devolvidos parcialmente. } \\
\hline & & & & & & & & & & \\
\hline & 01/out & 02/out| & 03/out & 04/out| & 05/out & 15/out| & 16/out| & 17/out & 18/out & Total \\
\hline Kit Confeccionado & 23 & 23 & 26 & 25 & 24 & 23 & 20 & 26 & 25 & 215 \\
\hline Kit Devolvido & 18 & 20 & 19 & 19 & 20 & 21 & 17 & 22 & 19 & 175 \\
\hline Cirugias Suspensas & 3 & 0 & 4 & 4 & 2 & 1] & 2 & 1 & 2 & 19 \\
\hline \multicolumn{11}{|c|}{$\begin{array}{c}\text { Da totalidade na amostragem, verificamos que } 77 \% \text { dos kits confeccionados foram devolvidos, desconsiderando as } \\
\text { cirurgias suspensas. }\end{array}$} \\
\hline & 01/out & 02/out & 03/out & 04/out & 05/out & 15/out & 16/out & 17/out & 19/outt & Total \\
\hline Devolvido Intacto & 0 & 0 & 0 & 0 & 0 & 0 & 0 & 0 & 0 & 0 \\
\hline Devolvido Parcial & 18 & 20 & 19 & 19 & 20 & 21 & 17 & 22 & 19 & 775 \\
\hline Kits não devolvidos & 2 & 3 & 3 & 2 & 2 & 1 & 1 & 3 & 4 & 21 \\
\hline Cirugias Suspensas & 3 & 0 & 4 & 4 & 2 & 1 & 2 & 1 & 2 & 19 \\
\hline
\end{tabular}

CONCLUSÃO: A readequação dos kits cirúrgicos e o aumento da adesão de utilização proporcionaram maior eficiência e eficácia aos processos desenvolvidos, otimizando o trabalho e diminuindo desperdícios além de melhorar as relações tornando o trabalho mais harmonioso e seguro. Diminuiu o retrabalho da farmácia satélite, pois minimizou as devoluções e reduziu o risco de suspensão cirúrgica por motivos extra paciente.

REFERÊNCIAS: (1) MACHADO, R F . PASCHOAL, M L H, YAMAGUCHI R Y. Reestruturação de preparo dos kits cirúrgicos para a implantação de um programa informatizado, Revista SOBEC: São Paulo, v 12, n 2, 2007. 